\title{
La ausencia de una verdadera humanidad ${ }^{1}$
}

\author{
The Absence of True Humanity
}

A ausência de uma verdadeira humanidade

\section{Luis Guillermo Jaramillo-Echeverri² Juan Carlos Aguirre-García ${ }^{3}$}

\section{Resumen}

El propósito que nos trazamos es contribuir en las discusiones acerca de la reconstitución de lo humano en una era en la que, aparentemente, se impone la disolución del sujeto. Parece que actualmente las humanidades están puestas en cuestión; sin embargo, lo que realmente está en cuestión parece ser su objeto mismo. En el presente artículo de reflexión pretendemos, a la luz de los trabajos del filósofo Emmanuel Levinas, examinar dos sentidos de inhumanidad presentes en la contemporaneidad: la libertad positivada y la universalidad impersonal de la verdad; asimismo, planteamos una propuesta en la que se discuta la posibilidad de una auténtica humanidad. Para ello, comenzamos señalando los rasgos de positivización que impregnan la vida actual; continuamos poniendo en cuestión los modelos universalistas de la verdad y concluimos, en el último apartado, sobre lo que denominamos lo humano de la humanidad.

\section{Palabras clave}

humanidades; ciencias humanas; enseñanza de las humanidades

\section{Abstract}

Our purpose is to contribute to the discussions about the reconstitution of humanity in a time when the dissolution of the subject apparently prevails. It seems that humanities have now been called into question; however, what is really in question appears to be its very object. In this reflection article we aim, following the works of philosopher Emmanuel Levinas, to examine two senses of inhumanity that are present in contemporaneity: positivized freedom and the impersonal universality of truth; we also offer a proposal that discusses the possibility of an authentic humanity. For this purpose, we begin by pointing out the features of positivization that pervade contemporary life; we continue by questioning the universalistic models of truth, and, in the last section, we conclude with what we call the humanity of mankind.

\section{Keywords}

humanities; human sciences; teaching humanities

1 Este artículo de reflexión forma parte de las discusiones adelantadas en los grupos de investigación Fenomenología y Ciencia (Categoría A1-Colciencias) y Kon-moción: Seminario Permanente Motricidad Humana. Se articula a la investigación doctoral en filosofía titulada: Crítica de Emmanuel Levinas a los paradigmas occidentales sobre el conocimiento y posibilidades para una racionalidad renovada en filosofía y en ciencias humanas y sociales (Medellín: Universidad Pontificia Bolivariana). Igualmente, es parte de la línea de Investigación Pedagogías de la Alteridad, de la cual es parte el proyecto: "Sentidos del contacto jóvenes universitarios". Los autores damos expreso crédito y mención a la Universidad del Cauca por el respaldo para la realización de estos trabajos.

2 Doctor en Ciencias Sociales - Educación, profesor titular del Departamento de Educación Física, Universidad del Cauca, Popayán, Colombia, ljaramillo@unicauca.edu.co

3 Magíster en Filosofía, profesor titular del Departamento de Filosofía, Universidad del Cauca, Popayán, Colombia, jcaguirre@unicauca.edu.co 


\section{Resumo}

Nosso propósito é contribuir nas discussões sobre a reconstituição do humano em uma era na que, aparentemente, se impõe a dissolução do sujeito. Parece que atualmente as humanidades estão em questão; contudo, o que realmente está em questão parece ser seu objeto mesmo. No presente artigo de reflexão visamos examinar, com base nos trabalhos do filósofo Emmanuel Levinas, dois sentidos de inumanidade presentes na contemporaneidade: a liberdade positivada e a universalidade impessoal da verdade; assim mesmo, apresentamos uma proposta na que se questiona a possibilidade de uma autêntica humanidade. Para isso começamos assinalando os rasgos de positivação que impregnam a vida atual; continuamos questionando os modelos universalistas da verdade e concluímos, na última seção, sobre aquilo que denominamos o humano da humanidade.

\section{Palavras chave}

humanidades; ciências humanas; ensino das humanidades

\section{Artículo recibido el 17 de noviembre de 2016 y aprobado el 28 de julio de 2017}

\section{Introducción}

En su libro Totalidad e infinito, el filósofo judío Emmanuel Levinas cita el siguiente verso del poeta Arthur Rimbaud: "La verdadera vida está ausente"; posterior a la cita, sin ambages, interpela al poeta: "pero nosotros estamos en este mundo" (2012, p. 27). El verso forma parte del poema "Délires I: Vierge folle. Lépoux infernal"; en él, el poeta narra las quejas y pesadumbres de una relación conflictiva, para nada ejemplo de cordialidad y buena convivencia; incluso, una frase antes y otra después del extracto, Rimbaud habla de la tragedia que vive el narrador: "Olvidé todo mi deber humano para seguirlo. ¡Qué vida! La verdadera vida está ausente. No pertenecemos al mundo" (Rimbaud, 2005, p. 280). El poema remite al olvido, a la falta de compromiso humano, hasta llegar al punto de no considerarse parte de este mundo; no obstante, reiteramos, Levinas interpela al poeta: "nosotros estamos en el mundo". El compromiso y la responsabilidad con lo humano van más allá del parentesco filial (un esposo infernal) o la identificación con un grupo o una cultura específica (una virgen loca).

Es cierto que nos encontramos en este mundo como in medias res, deseando un cielo nuevo, una patria nueva, una exterioridad donde encontremos una paz que tal vez no hemos experimentado jamás; el ser humano siempre ha abrigado una nostalgia de paraíso que quizás no encontrará mientras esté en este mundo. Sin embargo, estamos en un mundo donde ocurre todo: muerte y vida, violencia y acogimiento, indiferencia y solidaridad, odio y amor; pero es gracias a esta coartada que el Deseo de otra realidad es lo que nos posibilita estar atentos a otra vida, otra humanidad, una "vuelta hacia 'otra parte' y hacia 'lo de otro modo' y hacia 'lo otro"' (Levinas, 2012, p. 27). La primera sección de Totalidad e infinito, denominada Mismo y Otro, inicia con un apartado titulado: "Deseo de lo invisible"; Deseo absoluto que tiende hacia algo totalmente otro que desborda toda tentativa de satisfacción y que se alimenta precisamente por lo deseado.

En julio de 2016 murió Elie Wiesel, uno de los hombres que más buscó el establecimiento de la paz en el mundo, un sobreviviente de Auschwitz; a sus quince años sufrió el horror de la guerra viendo cómo su madre y hermana menor caminaban hacia los hornos crematorios, un lugar donde la inhumanidad de la vida, la animalidad, se presentaban con todas su fuerzas. Wiesel, premio Nobel de paz en 1986, permanentemente repetía una frase desgarrada de dolor pero con una gran dosis de esperanza: "los santos son los que mueren antes del final"4; esta frase nos remite "hacia otra parte"; es decir, no vivimos más que esta vida, pero es una vida alimentada por una trascendencia inagotable, deseante, que es la fuente que nos posibilita encontrar sentido a nuestra existencia. Decir que los santos mueren antes del final es renunciar a la invisibilidad de los que nos precedie-

4 Esta frase la referencia Miguel García-Baró (2007) para hacer notar cómo "el hombre no se rompe ni aún con la experiencia de lo absolutamente no humano [...] Los sobrevivientes han mutado su antigua naturaleza porque han comprobado que para el hombre es imposible lo inhumano [...] lección bien aprendida que se lleva a la práctica sobre los pobres, los extranjeros, las mujeres, los enfermos, los diferentes" (pp. 49-50). 
ron: seis millones de judíos asesinados que, en vida, "habían olvidado el sabor amargo de las lágrimas" (Wiesel, 2004, p. 137); pero también, es no dejar que se invisibilicen los muertos por ataques terroristas, $o$ inmigrantes ahogados que intentaron ingresar a un país que nunca sintieron como suyo. Asimismo, decir que los santos mueren antes del final es cargar con la vergüenza y la responsabilidad de que aún no hemos hecho lo suficiente; es más, nunca será suficiente, pues se trata de Desear una humanidad que aún continúa ausente, tal y como lo plantea E. Levinas:

... la no-correspondencia entre la muerte y un final que el sobreviviente constata no significa, pues, que la existencia mortal pero incapaz de pasar esté aún presente después de su muerte; que el ser mortal sobreviva a la muerte [como Elie Wiesel] cuya hora suena en el reloj común de todos los hombres. (2012, p. 56).

En la anunciada sección de Totalidad e infinito, Levinas menciona dos veces la palabra inhumanidad o falta de una verdadera humanidad. La primera está en el contexto de su exposición acerca del Deseo por lo invisible; la segunda en el contexto de la Metafísica que precede a la trascendencia. En ambos apartados el autor reclama la presencia de una humanidad en la que los vínculos humanos no sean cooptados por una ontología de la finitud, ni por la universalidad de una verdad impersonal donde las personas pasen a ser personajes ${ }^{5}$. Decir presencia-que no es contrario a ausencia o falta de algo-, es recordar la vida de los santos que nos precedieron y manifestar que su muerte no fue vana en este mundo. El presente escrito intenta mostrar estos dos sentidos de inhumanidad; pero a su vez, invoca una trascendencia, una ética que exceda el vilo de las humanidades, gracias a una relación interhumana que se reivindica a través de una significación, una enseñanza y una justicia, puestas en el mismo seno de la interacción o relación absoluta. Estas reivindicaciones se presentan tan solo como prolegómenos para posteriores desarrollos.

5 Para una explicitación de esta distinción entre personajes y personas, véase Jaramillo y Aguirre (2015).

\section{Una libertad positivada: la necesidad como subsistencia}

Podría decirse que, a lo largo del siglo pasado y lo que va del actual, el Deseo se ha presentado como una loca pretensión; una de las señales de este deseo es la inmediatez por lo efímero, que no solo acortó y acorta las distancias, sino que también parece haberlas borrado por completo. Tal inmediatez ha reducido las necesidades humanas o bien a simples maneras de subsistir, o bien a pseudo-necesidades que han sido creadas para saciar una sed de consumo, satisfacción que se requiere de inmediato. En cualquier caso, el deseo humano parece haberse reducido a la esfera de lo natural (animalidad) o de lo artificial (deseo por aquello que debe satisfacerse de inmediato), a la esfera de lo "a la mano". Para Levinas (2012),

... el hambre y el miedo pueden acabar con toda humana resistencia y con toda libertad [...] de esta animalidad no se trata de dudar. Pero ser hombre es saber que es así. La libertad consiste en saber que la libertad está en peligro. Y saber o tener conciencia es tener tiempo para evitar y prevenir el instante de la inhumanidad (p. 29).

De acuerdo con esta idea, podría sostenerse que actualmente la humanidad está viviendo un exceso de positividad. En consonancia con lo planteado por Levinas, el filósofo Byung Chul-Han (2012) ha diagnosticado la situación del mundo contemporáneo bajo la categoría de sociedad del cansancio; en esta se desenvuelve un sujeto que sufre una violencia interior, cuyo rasgo central es su resistencia a dejarse impactar por la exterioridad, especialmente por aquella provocada por otra persona. Según esto, lo que hace el sujeto es recogerse sobre sí mismo y hacer uso de una "libertad" que le hace presa de su propio desgaste por la acción continua de su propio rendimiento. En palabras de Chul-Han (2016), el individuo de la actual modernidad tardía

... se desprende cada vez más de la negatividad del otro. Su libertad se configura como libertad del otro, la cual revierte en un vínculo del yo consigo mismo cada vez más patológico. De ahí 
que el vínculo con el afuera, el objeto y el mundo se pierda cada vez más. (p. 75).

Esta asimilación está cargada de un exceso de positividad. Si bien en el siglo xx la adecuación del otro al mismo se daba a través de tácticas mediante las cuales un sujeto doblegaba las fuerzas del otro reduciendo su alteridad, en el xxi tal adecuación/ asimilación se refina, se hace más sutil, en la medida en que el sujeto no puede identificar la resistencia o exterioridad de este otro; más bien, la hace una extensión para seguir cumpliendo, ya no con las demandas o exigencias que vienen de afuera, sino con las del propio rendimiento personal. En esta adecuación, el sujeto no es puesto-en-cuestión por una exterioridad que viene del infinito; más bien, su mismidad se borra al creerse libre de todo, porque cree que es libre de todo. Dice Chul Han (2016):

El sujeto de rendimiento de la Modernidad tardía no está sometido a nadie. De hecho, ya no es un sujeto, pues ha dejado de serle inherente cualquier tipo de sujeción (subject to, sujét á). Se positiviza, se libra a un proyecto. La transformación de sujeto a proyecto no hace que la violencia desaparezca. En lugar de una coacción externa aparece una coacción interna, que se ofrece como libertad. Este desarrollo está estrechamente relacionado con el modo de producción capitalista. Porque a partir de cierto nivel de producción, la autoexplotación es mucho más eficiente, mucho más potente que la explotación del otro, porque va aparejada con el sentimiento de libertad. (p. 14) [énfasis en el original].

Podría confrontarse este planteamiento con la ya citada frase de Levinas según la cual "la libertad consiste en saber que la libertad está en peligro". Para Levinas (2012), hoy se pone en cuestión no solo la libertad del mismo, frente a la manera desinteresada y violenta con la que actúa frente al otro, sino que también es puesta en cuestión la libertad con la que el mismo se autoagrede. En los análisis levinasianos esto resulta de una libertad surgida de la obediencia al ser: no es el hombre el que tiene la libertad, sino que es la libertad la que tiene al hombre; de tal suerte que como hombre se presiona y autoagrede afectando su propia interioridad. Esto mismo lo explicita Chul Han (2016):

[El sujeto] se obedece a sí mismo. Es un empresario de sí mismo. De este modo, se deshace de la negatividad del demandante otro. Esta libertad del otro, sin embargo, no solo es emancipadora y liberadora. La dialéctica de la libertad se basa en que esta cree nuevas obligaciones. La libertad del otro se convierte en una relación narcisista con uno mismo, responsable de muchas de las perturbaciones psíquicas del sujeto de rendimiento. (p. 48).

No es fortuito, entonces, que las principales enfermedades del presente siglo no sean solo físicas, también son psíquicas: enfermedades que remiten a un ser agotado, o más bien, con el alma calcinada; un ser ávido de vivencias sobre sí mismo, de diversión inagotable e inaguantable en la que la vida, la buena vida, pierde duración y consistencia (en el entendido que la hiperactividad y el rendimiento del proceso de vida logren compensar, de cierta manera, el vacío existencial que se tiene). Tanto Levinas como Chul-Han dan cuenta de esto: para el primero, "el ser encarcelado que ignora su prisión está en casa" (Levinas, 2012, p. 20); para el segundo, "una sociedad gobernada por la histeria de la supervivencia es una sociedad de zombies que no son capaces de vivir ni de morir" (Chul Han, 2016, p. 39). En consecuencia, ambos autores coinciden en señalar que las vivencias reemplazan las experiencias que se dan en el encuentro con el Otro: para Levinas, "la experiencia significa precisamente relación con lo absolutamente otro, $\mathrm{o}$ sea, con lo que siempre desborda el pensamiento" (2012, p. 18); para Chul-Han, "estas experiencias son alter-adoras. No obstante, las vivencias, suponen una extensión del yo en el otro, en el mundo. Son igual-adoras... si se pierde del todo la relación con el otro, no se puede constituir una imagen sólida del yo" (2016, pp. 49-50).

En el planteamiento levinasiano es claro que no puede existir una alteridad o relación radical si ambos interlocutores, Yo y Otro, no están instalados en su propia identidad, en su absolutez: "la alteridad no es posible más que partiendo de mi" (Levinas, 2012 , p. 35), por cuanto cada uno es otro para el 
otro; sin embargo, al yo perder una imagen sólida de sí mismo, la verdadera relación, la asimetría, pierde toda su fuerza, pierde su infinito. En la instantaneidad de la vida los seres intentan lo imposible porque creen que todo les es posible. La asistencia dirigida a un otro se cambia por la subsistencia del Mismo; se trataría de un ser necesitado que intenta abastecer el vacío del cual está llena su alma. En este sentido, se pierde la trascendencia del Deseo pues, como dice Levinas, "El Deseo es una aspiración que lo Deseable anima. En cambio, la necesidad es un vacío del Alma, parte del sujeto" (2012, p. 64). De este modo, la necesidad no vendría a satisfacer ni siquiera un gozo o disfrute del mundo, sino la subsistencia amparada en un poder que recaería en su propia humanidad y que terminaría, por tanto, fracturando su propia existencia. Como diría Catherine Chalier (2004), el poder fascina al hombre, este se "apasiona ante las proezas técnicas y su poder cada vez más creciente de dominación de la alteridad de las cosas y de las personas" (p. 103). Al reducir la alteridad a necesidad, la humanidad del sujeto queda disimulada en una mirada sombría que le hace perder toda fe o convicción en lo humano, hasta llegar a la trágica afirmación de Rimbaud: "la verdadera vida está ausente".

$\mathrm{Si}$, como se ha visto en Levinas, la exterioridad no viene del Mismo sino de la irrupción del Otro absoluto que altera la tranquilidad del Mismo, o más bien, el agotamiento y aburrimiento del Mismo, entonces podemos atrevernos a decir que es gracias a la irrupción que hace el Otro ante el Mismo, inversión de los términos, que logra sacar al Mismo de su pesadez mortífera. Abrirse al Otro implicará, inicialmente, exponerse, salir de sí con una salida que no permite retorno, es decir, al abrirse al Otro, al agrietar el narcicismo centrípeta del mismo, se genera un cambio que le lleva a no volver a ser el mismo. También podríamos aventurarnos a decir que el Otro, en su infinito, recupera las fuerzas que el Mismo ha gastado pensando excesivamente en su propia mismidad. En este sentido, el yo es recuperado y "dotado de vida personal [...] No se integra a ningún destino, se sobrepasa a sí mismo en el Deseo que le viene de la presencia de Otro" (Levinas, 2012, p. 62). Gracias al Otro, del cual no podemos inventarnos el objeto de su amor, sino que procede de él, es que la presencia de su humanidad viene a restaurar nuestra ausencia, precisamente, por su humanidad.

\section{La universalidad impersonal de la verdad}

Habiendo analizado un primer sentido de inhumanidad, esto es, aquella que brota de la reducción del deseo a mera positivización, podemos considerar el segundo sentido concerniente a los modos como se enuncia la verdad, modos que la reducen a objetivismo y universalización, haciendo perder el contacto con la vida misma de lo humano.

De este modo, comenzamos describiendo ciertas características de la concepción epistemológica de la verdad. La primera de ellas es su obsesión por la objetividad, entendida esta como la presencia mínima en lo enunciado del sujeto que enuncia. La objetividad de una verdad se presenta como justificación demostrada a través de evidencias que se pueden comprobar en un mundo físico. En este sentido, la ciencia pone como fundamento para sus certezas lo empírico de este mundo, gracias a la interrogación incesante que el hombre le hace, incluso, a las mismas relaciones humanas. Producto de este interrogante se elabora, se crea una teoría, que Levinas denomina inteligencia o "-logos del ser-, o sea, una manera de abordar al ser conocido que su alteridad respecto del ser cognoscente se desvanece" (2012, p. 38). De acuerdo con esto, el cognoscente se mueve en una libertad espontánea que le permite crear categorías no solo de lo que ya ha leído y asimilado de él, sino de lo que pueda seguir diciendo o tematizando de él. En tal virtud, el cognoscente no solo asimila al otro a través de la teoría, su inteligencia, sino que de antemano la teoría se ha convertido en el fundamento para comprenderlo, conocer-lo.

En este sentido, no se está haciendo referencia solo a la manera como el cognoscente asimila al conocido, sino que el fundamento de este se llama teoría, de la cual se extraerá una evidencia para seguir 
haciendo más teoría, ante lo cual se encapsula, o queda envuelto, el mismo cognoscente, el conocido y lo conocido. A decir de Levinas, este encapsulamiento genera un espacio de neutralidad; así, tanto Mismo como Otro abdican en lo general de lo pensado y, por tanto, se convierten en seres de obras que pasan de mano en mano y configuran la universalidad anónima de la historia. Desde esta consideración,

... abordar a alguien partiendo de sus obras es entrar en su interioridad como practicando en ella un boquete. El otro queda sorprendido en su intimidad, en la que, desde luego, se expone, pero no se expresa, como los personajes de la historia. Las obras significan a su autor, pero indirectamente, en tercera persona. (Levinas, 2012, p. 68).

Por cuanto esta es una actitud que caracteriza a la mayoría de los trabajos de investigación, podrían tomarse múltiples casos para ejemplificarlo. Consideremos solo uno: en un estudio reciente, realizado en el programa de Fisioterapia de la Universidad del Cauca, titulado: Procesos de contacto en estudiantes de fisioterapia, encontramos que el fundamento para que los estudiantes puedan moverse con destreza en una sesión de masaje terapéutico es teniendo la teoría como fundamento, la cual aplican gracias a la mecánica corporal que pueden ejercer al otro a través del contacto. La teoría en este sentido pasa a ser un empoderamiento y una autoridad en algo tan humano como el encuentro con la piel. En el estudio se observó la dificultad que tenían los estudiantes para tocar y sentirse tocados; manifestaron temor, vergüenza, recelo, así contaran con los principios teóricos dados por la técnica del masaje (Torres y Jaramillo, 2016). Desde esta lógica, la verdad obtenida mediante el esfuerzo de la teoría, la inteligencia, que debería reconciliar a las personas, existe anónimamente. La verdad se presenta en una universalidad impersonal, y en ello hay otra inhumanidad, pues la humanidad del Otro abdica o se rinde a la conceptualización.

Levinas otorgó a este englobamiento mismo-otro, a través de la teoría como inteligencia, el título de ontología ${ }^{6}$, por la cual se "reduce lo Otro a Mismo, [se] promueve la libertad, que es la identificación de Mismo que no se deja alienar por Otro" (2012, p. 38). Esta libertad del Mismo, que es el cognoscente, es precisamente lo que el filósofo de la alteridad pone en cuestión: el libre ejercicio ontológico que reduce a Otro. Es a este cuestionamiento, a esta crítica de la reducción, que llamamos ética; es decir, lo extranjero del Otro, su irreducibilidad a mis pensamientos. Por tanto, en esta inversión de los términos, la crítica del saber no comportaría la inteligencia o lucidez de un Mismo para filtrar los objetos del mundo o a Otro, hacerlo totalidad ${ }^{7}$. El saber original, la esencia crítica del saber, "se produce concretamente como la puesta en cuestión de Mismo por Otro, o sea, como ética" (Levinas, 2012, p. 39). Esta crítica original precede a todo dogmatismo, a toda reflexión de captura, a todo método, a todo objeto o instrumento conocido con el que se quiera comprender al Otro.

Podríamos preguntarnos, entonces, ¿cuál es la verdad que emerge de esta crítica primera, de este emplazamiento al recusar la verdad como ontológica? En Levinas (2012), la verdad supone la justicia pues al "pretender integrar al yo y lo otro es un espíritu impersonal, esta pretendida integración es crueldad e injusticia, o sea, ignora al Otro" (p. 50). Por consiguiente, esta verdad como presencia del Otro en mí se da desde otros modos de ser, como:

6 Según Levinas (2012), la obra de la ontología consiste en captar al individuo -lo único que existe-, no en su individualidad sino en su generalidad -lo único que hay en la ciencia-. La relación con lo Otro no se cumple aquí más que a través de un tercer término que yo encuentro en mí. El ideal de la verdad socrático descansa, pues, sobre la suficiencia esencial de Mismo, sobre su identificación de ipseidad, sobre su egoísmo. La filosofía de una egología.

7 En Levinas pueden encontrarse tres instancias que configuran las relaciones enmarcadas en la Totalidad, yo y otro encapsulados en un sistema cerrado, donde la alteridad se suprime y todo queda reducido a Mismo: en primera instancia, dentro del Mismo: yo que se mira "como si" fuese otro en su interioridad, concluyendo que no hay tal distinción y confirmando su identidad $(A=A)$; en segunda instancia, yo que se enfrenta al mundo como lo distinto de sí, pero yo que con el tiempo se habitúa, "encuentra en el mundo un lugar y una casa" (Levinas, 2012, p. 61) y el mundo se torna "a la mano", como posibilidad y espacio para ejercer mi libertad, siendo dueño y señor de todo lo extraño; incluso, de mis congéneres. En última instancia, yo que se encuentra ante el Otro y lo re-presenta de acuerdo con imágenes previas, lo comprende basado en situaciones anteriormente vividas, lo adecúa a lo conocido y lo subsume en pensamiento cogitante (véase Jaramillo y Aguirre, 2010). 
a) La verdad no procede de un esfuerzo cognitivo de Mismo y la pasividad de Otro. Esto es asimilación, tematización. b) Para que emerja una verdad con justicia debe existir una separación radical en la que ambos seres estén plenamente instalados y autónomos; sin separación no habría verdad, solo habría habido ser. c) La verdad es una búsqueda que se da en medio de gajes y peligros que se despliegan en la aparición de las formas gracias a la epifanía de la distancia. No podríamos ver la verdad en el Otro más que como se nos presenta el Otro; pues a pesar de ver que algo le falta, no le hace falta nada; y d) La búsqueda de la verdad no remite a la teoría de un ser privilegiado, sino que es acontecimiento que se hace Deseo del Otro; o sea, una verdad jamás alcanzada; cuanto más nos acercamos a ella, más se aleja de nosotros; pero es precisamente este incesante movimiento de excedencia el que alimenta nuestro Deseo de seguir comprendiendo la humanidad infinita de ese Otro a partir de su testimonio y no de su representación o desvelamiento. Desde esta perspectiva, es el testimonio el que nos permite dirigirnos "hacia una verdad que escapa a la racionalidad científica y técnica, una verdad que permite cuidar el secreto de lo humano precisamente porque aquel que es animado por esa verdad no busca apoderarse de ella" (Chalier, 2004, p. 99).

Estas ideas las condensa Levinas de la siguiente manera:

La verdad se busca en lo otro, pero por aquel al que no le hace falta nada. La distancia es infranqueable, y a la vez, está franqueada. El ser separado está satisfecho, es autónomo y, sin embargo, busca lo otro con una búsqueda que no va aguijoneada por la carencia de la necesidad ni por el recuerdo de un bien perdido; tal situación es lenguaje. La verdad surge allí donde un ser separado de lo otro no se hunde en éste sino que le habla. (2012, p. 62).

En esta idea levinasiana, que puede servir como conclusión, la universalidad anónima de la verdad pierde todo su aguijón; por tanto, se rescata la presencia viva de una humanidad que sale del anonimato, de su universalidad ignota, y Desea una paz -una verdad- que está por encima de "la victoria de unos y la derrota de otros, o sea, con los cementerios o los futuros imperios universales" (Levinas, 2012, p. 346).

\section{Significación, enseñanza y justicia: lo humano de la humanidad}

Las humanidades se han tematizado, han llegado a ser producto de un sistema que encaja en la reflexión de un hombre, un anónimo (que aprehende teoría y teoriza), y que necesita conocerse a sí mismo por la vida anónima de los otros. El vilo, la vigilancia de las humanidades, de otra humanidad, no se puede mantener en una actitud crítica del saber más que cuestionando todo intento de homologación en la que Otro queda adecuado en la no-violencia de la tematización ${ }^{8}$, que es, sin embargo, más violenta que aquella que hiere o ataca; allí reina la indiferencia. Pero también, las humanidades deben mantenerse en crítica incesante ante los agotamientos sociales en los que se observa a un sí mismo cansado, así como las razones impersonales de una verdad que parece englobar eternamente las relaciones de los seres humanos; allí reina el cinismo. El primado de la ética en las humanidades implicará que de ellas emerja una interacción humana que aún sigue ausente en las mismas humanidades ${ }^{9}$; para ello, se debe partir: a) no de lo ya conocido, sino de la significación misma que da origen a todo conocer; b) de una enseñanza que acoja al otro en su expresión, y c) de una justicia que recuse una verdad des-velada o anónima. A continuación esbozaremos estas rutas con la esperanza de ampliarlas en futuros desarrollos.

8 Para García-Baró: “El principio ético-político del humanismo universal es humanismo a secas: la fórmula del mandamiento moral central por la que se experimenta la necesidad de respetar a cada individuo de nuestra especie como a un fin en sí mismo y la de rechazar la manipulación con vistas a ningún otro fin ulterior y que no vaya ínsito en su misma naturaleza de hombre" (2012, p. 117).

9 Según Levinas: todo lo que no puede retrotraerse a una relación interhumana representa no la forma superior sino la definitivamente primitiva de la religión (2012). 
En primera instancia, se ha diagnosticado que el agotamiento o cansancio de lo humano tiene su raíz en la propia libertad que se cree poseedora y dominadora de todo lo que se le presente, incluso de su propia interioridad, haciendo de ella un objeto de producción. En igual medida, que el afán por tematizar todo bajo la lente universalista ha hecho que la verdad se torne un objetivismo donde la humanidad, o adopta el carácter de objeto, o se suprime en aras de una neutralidad valorativa. En tal sentido, es preciso anclar las discusiones sobre lo humano y la verdad de lo humano en terrenos allende la interioridadmismidad y el objetivismo. Si el hecho fundamental de la existencia es el estar con otros, en proximidad con otros, ni el Mismo anclado en su mismidad, ni la verdad que se pretende objetiva y neutral podrán encontrar fundamento a la significación, pues se caería en una petición de principio que ahondaría las paradojas epistémicas. El fundamento debe hallarse, justamente, en el otro que descentra al yo y en la verdad que se ofrece a este otro: verdad como donación (plenificación del concepto de "dato", lo dado), como generosidad, que se hace responsable del otro. En consecuencia, solo reconociendo que la humanidad auténtica se constituye en la relación cara-a-cara, puedo comprender que todos los demás sentidos, incluso los cognoscitivos, proceden de esta relación, de este uno-para-Otro.

En segunda instancia, esta relación cara-a-cara implica acoger al Otro en su expresión; acogida que desborda la idea que de él se llevaría a un pensamiento. Es decir, recibir del Otro más allá de la capacidad del Yo; lo cual significa exactamente tener la idea de su infinito. Esto es, ser enseñado. Enseñanza que viene del exterior, aporta más de lo que yo contengo (Levinas, 2012). Pero también es discurso, acogida que se encuentra por fuera de las dicotomías que rigen para las cosas; en tal caso, continúa el filósofo, la explicación de un pensamiento no puede hacerse más que al alimón. Interacción humana que nos permite aprender no solo de lo enseñado sino del enseñante mismo como maestro que, por lo general, ha caído en las representaciones de la tematización. Sin embargo, cuando la temati- zación nos seduzca, no la esquivemos, busquemos en sus resquebrajamientos la humanidad de este Otro... busquemos su enseñanza.

Finalmente, como consecuencia del afincamiento de la auténtica humanidad en la relación con el Otro, fuente de toda significación, y en la acogida de este Otro como Maestro, en su dimensión de altura, no queda más que insistir en la necesidad de superar la condición de anonimato que pretende darse a la verdad e instaurar en ella la dimensión de justicia. En la propuesta levinasiana, la justicia no tiene que ver, en estricto sentido, con dar a cada cual lo que le corresponde, sino en responder con rectitud al Otro. De acuerdo con esto, en vez de desentrañar o desvelar lo humano de lo humano -lo cual se constituiría en la raíz de su propia inhumanidad o, como lo ha presentido Foucault, en su disolución-, las humanidades se esforzarían por retornar a las relaciones de justicia, cuyo indicador sería la responsabilidad con el Otro. En tal caso, las humanidades, lejos de hacer el juego a discursos tematizadores, podrán filtrar en sus hallazgos el esplendor de la infinitud del Otro, Otro que exige respuesta y que lleva en su rostro el imperativo: “¡No matarás!”. La ausencia de una verdadera humanidad se hace palpable en los discursos que cohonestan, incluso, con la aniquilación de lo humano.

\section{Conclusión}

El iniciar el artículo con la objeción que un filósofo hace a un poeta, en torno a la auténtica trascendencia y la imposibilidad de eludir los compromisos terrenos, sirvió de escenario para introducir una discusión acerca del papel que hoy desempeñan las humanidades, especialmente en momentos en los que estas se han puesto en vilo. En el artículo se consideraron dos síntomas contemporáneos de la inhumanidad en la que estamos inmersos, que se ha vuelto nuestra atmósfera y, en razón de ello, casi ni notamos sus consecuencias. Tanto la cristalización del deseo en satisfacción de necesidades susceptibles de complacencia como la verdad que se pretende universal han llevado al humano contemporáneo a dudar de su carácter trascendente, limitándose a 
los estrechos márgenes en los que la totalidad lo subsume. La apuesta de este trabajo consistió en abrir rutas para discutir otros aspectos conducentes a poner en cuestión la inhumanidad palpable en la contemporaneidad. Significación auténtica, el conocimiento como enseñanza que se recibe de Otro y la imposibilidad de eludir la responsabilidad para con el otro en relaciones de justicia, son apuestas por unas humanidades que partan de lo auténticamente humano, así la búsqueda de lo auténtico sea considerado por los negadores de la trascendencia como un sueño ya soñado.

\section{Referencias}

Chalier, C. (2004). Dios después de la Shoah. En F. Bárcena et ál. (eds.), La autoridad del sufrimiento. Silencio de Dios y preguntas del hombre (pp. 87-106). Barcelona: Anthropos.

Chul Han, B. (2012). La sociedad del cansancio. Barcelona: Herder.

Chul Han, B. (2016). Topología de la violencia. Barcelona: Herder.
García-Baró, M. (2007). De estética y mistica. Salamanca: Sígueme.

García-Baró, M. (2012). Elementos de antropología filosófica. México: Jitanjáfora, Morelia Editorial, pp. 187-211.

Jaramillo, L. y Aguirre J. (2010). Levinas y las ciencias sociales: fundamentos epistémicos desde la alteridad. Folios. 31, 33-20.

Jaramillo, L. y Aguirre, J. (2015). De personajes a personas: una aproximación ético-epistemológica a la investigación en educación. Revista de Investigaciones, 15(2), 146-156.

Levinas, E. (2012). Totalidad e infinito. Ensayo sobre la exterioridad. Salamanca: Sígueme.

Rimbaud, A. (2005). Rimbaud. Complete works, selected letters. A bilingual edition. Chicago y Londres: The University of Chicago Press.

Torres, M. V. y Jaramillo, L. G. (2016). Por los intersticios del contacto: procesos relacionales en estudiantes universitarios. Nómadas. 44, 185-199.

Wiesel, E (2004). La noche. En: F. Bárcena et ál. (eds.), La autoridad del sufrimiento. Silencio de Dios y preguntas del hombre (pp. 87-106). Barcelona: Anthropos. 